\title{
Fabrication and Characterization of PZT Suspensions for Stereolithography based on 3D Printing
}

\author{
JaeMin Cha, Jeong Woo Lee, Byeonghoon Bae, Seong-Eui Lee, and Chang-Bun Yoon ${ }^{\dagger}$ \\ Department of Advanced Materials Engineering, Korea Polytechnic University, Siheung 15073, Korea \\ (Received May 10, 2019; Revised July 9, 2019; Accepted July 9, 2019)
}

\begin{abstract}
PZT suspensions for photo-curable 3D printing were fabricated and their characteristics were evaluated. After mixing the PZT, photopolymer, photo-initiator, and dispersant for $10 \mathrm{~min}$ by using a high-shear mixer, the viscosity characteristics were investigated based on the powder content. To determine an appropriate dispersant content, the dispersant was mixed at 1, 3, and $5 \mathrm{wt} \%$ of the powder and a precipitation test was conducted for two hours. Consequently, it was confirmed that the dispersibility was excellent at $3 \mathrm{wt} \%$. Through thermogravimetric analysis, it was confirmed that weight reduction occurred in the photopolymer between 120 ? and 500?, thereby providing a debinding heat treatment profile. The fabricated suspensions were cured using UV light, and the polymer was removed through debinding. Subsequently, the density and surface characteristics were analyzed by using the Archimedes method and field-emission scanning electron microscopy. Consequently, compared with the theoretical density, an excellent characteristic of $97 \%$ was shown at a powder content of $87 \mathrm{wt} \%$. Through X-ray diffraction analysis, it was confirmed that the crystallizability improved as the solid content increased. At the mixing ratio of $87 \mathrm{wt} \%$ powder and $13 \mathrm{wt} \%$ photo-curable resin, the viscosity was $3,100 \mathrm{cps}$, confirming an appropriate viscosity characteristic as a stereolithography suspension for $3 \mathrm{D}$ printing.
\end{abstract}

Key words : PZT ceramics, 3D printing, Stereolithography, PZT Suspensions, Viscosity

\section{Introduction}

$\mathbf{P}$ ZT is a typical piezoelectric ceramic and has a perovskite structure that shows polarization characteristics at below the Curie point. Moreover, it has high dielectric and piezoelectric characteristics at the morphotropic phase boundary, which is a phase boundary region of tetragonal and rhombohedral phases. PZT has excellent piezoelectric characteristics and is used in various piezoelectric devices such as piezoelectric sensors, actuators, and power generation devices. ${ }^{1-5)}$ Particularly, when a composite is formed by mixing PZT ceramic and polymer, $d_{13}$ and $d_{23}$ values approach 0 and consequently, a high value of $d_{h}$, a piezoelectric constant, can be obtained. Furthermore, the content ratio of PZT can be reduced to $20 \%$ in the composite because a polymer is mixed in, and consequently, a low acoustic impedance value can be obtained. Such a piezoelectric composite is produced in a desired shape by performing heat treatment at high pressure and temperature after pouring the sludge made by mixing PZT ceramic and binder in the pre-fabricated mold, or processing the sintered body or green body through micromachining. In the case of fabri-

\footnotetext{
${ }^{\dagger}$ Corresponding author: Chang-Bun Yoon

E-mail : cbyoon@kpu.ac.kr

Tel : +82-31-8041-0596 Fax : +82-31-8041-0599

ORCID

https://orcid.org/0000-0002-9640-0804
}

cating a piezoelectric composite by using a mold, as the mold is fabricated in advance according to the shape, the following limitations exist: the process is complex and the fabrication requires a large amount of time and cost. Furthermore, in the case of using the micromachining process, a loss occurs during the process and it is limited to the fabrication of actuators having various structures. ${ }^{6-8)}$

Recently, studies have been actively conducted on techniques to fabricate various shapes of ceramic products by using the $3 \mathrm{D}$ printing method. Ceramics are fabricated in various shapes by using the stereolithography-based 3D printing method, which cures a photopolymer using UV light and deposits it one layer at a time because it is difficult to apply the direct printing method, which melts it by using laser. This is because ceramics have excellent temperature stability. ${ }^{9-13)}$ In the case of performing $3 \mathrm{D}$ printing by mixing ceramic powder and photopolymer, the process and sintering characteristics of ceramic suspensions used in the stereography-based 3D printing are determined based on the viscosity and solid content. If the viscosity is too low, the deviation between the densities of upper and lower parts becomes large after printing because precipitations are produced during the printing. If the viscosity is high, a problem may occur in the fluidity of the suspension. In the case of ceramic products prepared using stereolithography-based 3D printing, as a photo-sensitive polymer is mixed in for photo-curing, a high-density ceramic sintered body can be fabricated by optimizing the binding process and sintering 
process. ${ }^{14-18)}$ This study fabricated high-density sintered bodies through heat-treatment process after fabricating ceramic suspensions by changing the ceramic powder and photopolymer ratio. To investigate the fluidity using the mixing ratio of the suspension, the viscosity was evaluated, and to investigate the density characteristics, the sinterability was evaluated by using the Archimedes method and scanning electron microscopy (SEM). To investigate the crystallizability of the PZT sintered body, X-ray diffraction (XRD) analysis was performed based on the powder content.

\section{Experimental Procedures}

As shown in Fig. 1, PZT-5A powder (Kyungwon Ind. Co., Korea) and 1,6-hexanediol diacrylate (HDDA, Sigma-Aldrich, US) were used as source materials to fabricate the PZT suspensions, and to improve the dispersity, BYK-142 (BYK, Germany) was used as a dispersant. As for the photo-initiator, 2,4,6-trimethylbenzoyl-phosphineoxides (TPO, SigmaAldrich, US) were used, which react in the UV wavelength range $350 \mathrm{~nm}-430 \mathrm{~nm}$. The mixing ratios of the PZT powder and photo-curable resins were selected as 80:20, 82:18, 85:15, 87:13, and 88:12 (photopolymer, photo-initiator, dispersant). Moreover, to determine the dispersant content, the dispersity was evaluated by changing the dispersant content to 1,3 , and $5 \mathrm{wt} \%$. After weighing the source materials according to the mixing ratio, premixing was performed and by using a high-shear mixer (Thinky Mixer, Japan), they were mixed at 1,500 rpm for $10 \mathrm{~min}$. The viscosity was measured for each mixing ratio by using a viscometer (Viscometer dv-ii+, Brookfield, US) to evaluate the fluidity of the ceramic suspensions. After curing the mixed PZT suspensions with $385 \mathrm{~nm}$ UV LED, the debinding temperature was measured using thermogravimetric analysis (TGA 4000, PerkinElmer, US) to select the heat-treatment condition; subsequently, debinding was conducted by heating at a rate of $1^{\circ} \mathrm{C}$ per min from $280^{\circ} \mathrm{C}$ to $500^{\circ} \mathrm{C}$, and they

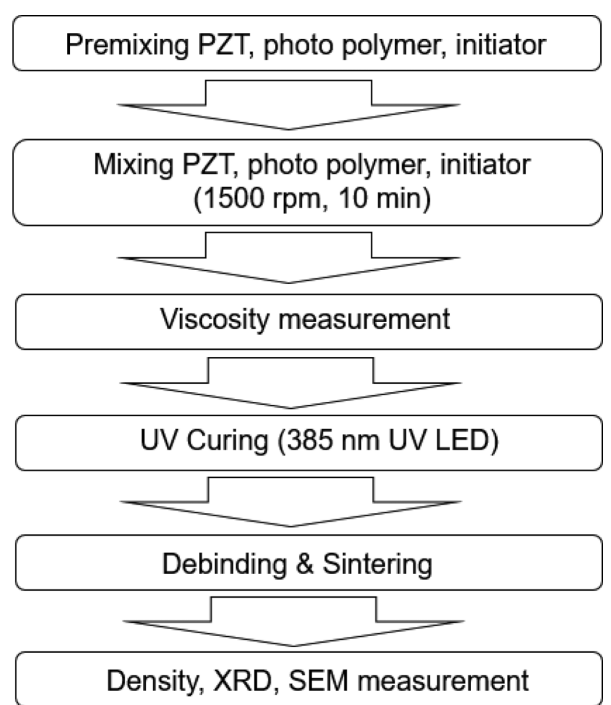

Fig. 1. Process flow for the experiments of PZT suspensions. were sintered at $1,200^{\circ} \mathrm{C}$ for $2 \mathrm{~h}$. The density of the fabricated sintered body for different mixing ratios was measured by using the Archimedes method, and the surface of the sintered body for different mixing ratios was examined by using SEM (Nova NanoSEM230, FEI, US). The crystallizability was investigated by using XRD (D2 PHASER, Bruker, Germany).

\section{Results and Discussion}

\subsection{Evaluation results of viscosity according to changes in PZT powder content}

The ceramic suspensions should be mixed with an appropriate viscosity that ensures sufficient fluidity in order to apply them to the photo-curable 3D printing process. Table 1 shows the mixing ratios used for the fabrication of suspensions according to the PZT and resin contents. When the ratio of PZT and resin was $80: 20$, vol\% was $34.1 \%$. As the PZT content increased, vol\% also increased and became $48.7 \%$ at $88: 12$. Fig. 2 shows the result of measuring the viscosity of the suspensions to check the mixing ratio providing the appropriate viscosity for printing. In the results of measuring the viscosity by increasing the PZT powder content, the viscosity was approximately $800 \mathrm{cps}$ at $82 \mathrm{wt} \%$, but the viscosity increased to $3,100 \mathrm{cps}$ at $87 \mathrm{wt} \%$ and $4,700 \mathrm{cps}$ at $88 \mathrm{wt} \%$. This confirms that the viscosity increases rapidly as the solid content increases.

Table 1. Suspension Mixing Ratio According to PZT Contents

\begin{tabular}{cccc}
\hline PZT & $\begin{array}{c}\text { Photopolymer, } \\
\text { Initiator }\end{array}$ & Dispersant & Vol\% \\
\hline 80 & 17 & 3 & 34.1 \\
82 & 15 & 3 & 37.1 \\
85 & 12 & 3 & 42.3 \\
87 & 10 & 3 & 46.4 \\
88 & 9 & 3 & 48.7 \\
\hline
\end{tabular}

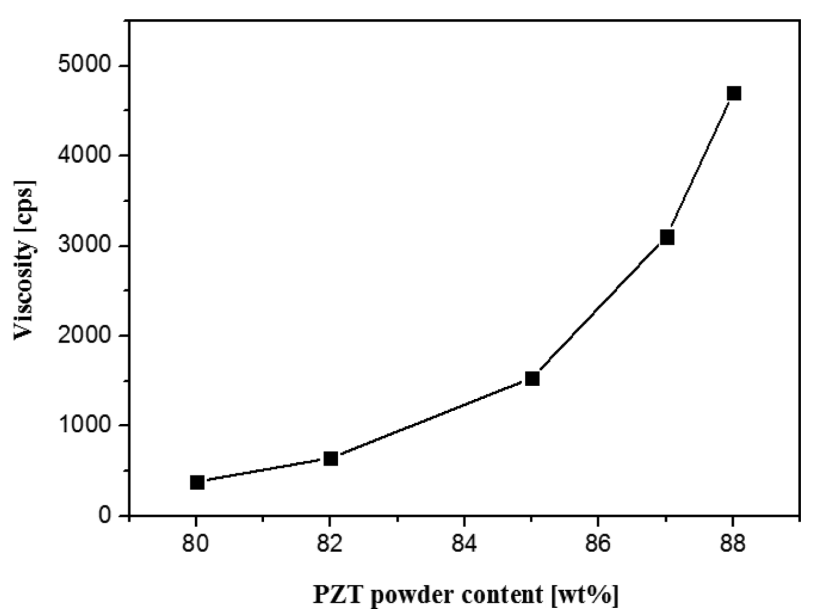

Fig. 2. Viscosity changes for the PZT powder contents of 80 , $82,85,87$, and $88 \mathrm{wt} \%$. 


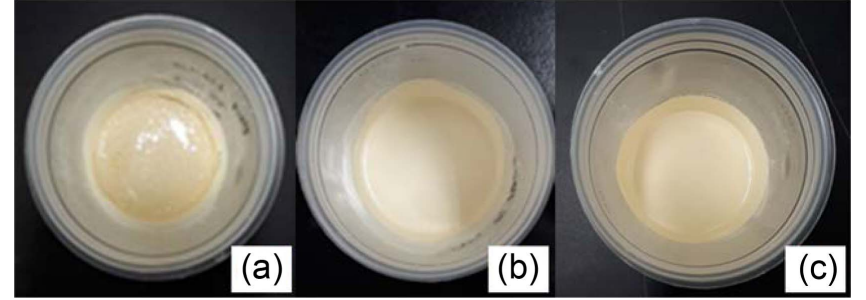

Fig. 3. Dispersion test results while changing the amount of dispersent to (a) $1 \mathrm{wt} \%$, (b) $3 \mathrm{wt} \%$, (c) $5 \mathrm{wt} \%$.

\subsection{Dispersion test based on the changes in disper- sant content}

Figure 3 shows images of the dispersion test based on the changes in dispersant content. By fixing the powder content at $87 \mathrm{wt} \%$ and changing the dispersant content to 1,3 , and $5 \mathrm{wt} \%$ of the powder, the dispersion test was performed.

After mixing, the suspension was maintained at room temperature for $2 \mathrm{~h}$, and then, the occurrence of dispersion of the powder was checked. In Fig. 3(a), where the dispersant content was the lowest at $1 \mathrm{wt} \%$, the powder and the resin was not dispersed. When the suspensions were fabricated with the dispersant contents of 3 and $5 \mathrm{wt} \%$ of the powder, confirmed that the powder was well dispersed in the resin at room temperature for $2 \mathrm{~h}$, as shown in Fig. 3(b) and (c), respectively. The viscosity was measured according to the amount of dispersant. When the dispersant was not mixed, the slurry was not mixed. When the dispersant amount was $1 \mathrm{wt} \%$, the viscosity was $6475 \mathrm{cps}$. As the amount of dispersant was increased to $3 \mathrm{wt} \%$, the viscosity was about $3100 \mathrm{cps}$, and when added $5 \mathrm{wt} \%$, the viscosity was about $2495 \mathrm{cps}$. The viscosity improvement effect was less than $3 \mathrm{wt} \%$ at $5 \mathrm{wt} \%$, and the amount of dispersant was selected to be $3 \mathrm{wt} \%$. Therefore, they were confirmed to be appropriate suspensions as it was predicted that no phase separation would occur during the $3 \mathrm{D}$ printing process. As the photopolymer content would decrease and a problem would occur in the photo-curing if the dispersant content became too high, the dispersant content was fixed at $3 \mathrm{wt} \%$.

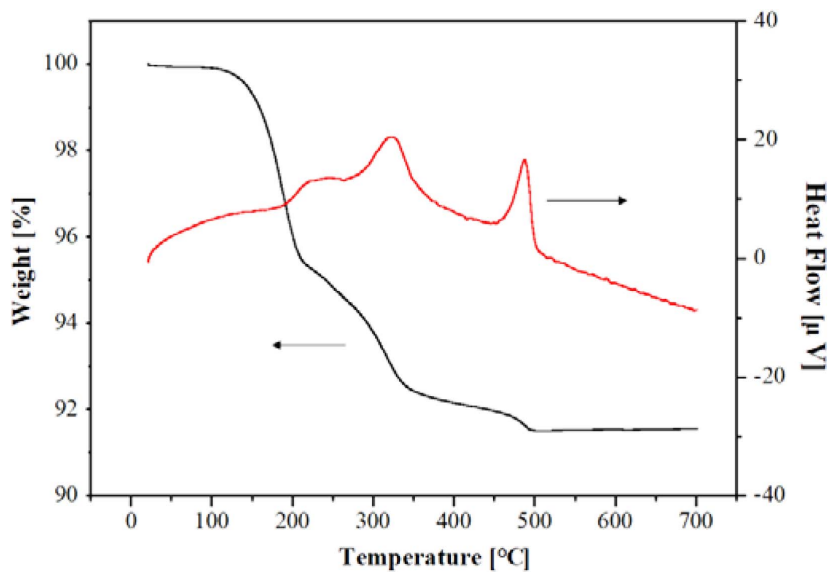

Fig. 4. TG-DTA analysis for the PZT/polymer ratio of $87: 13$.

\subsection{TG-DTA analysis results of suspensions}

In the PZT suspensions, inorganic PZT and organic resins such as photopolymer and dispersant are mixed, and the resin, which is a polymer type, must be completely removed through heat treatment so that only the inorganic PZT remains after sintering. To establish the debinding process, which removes the polymer when sintering, the suspension mixed with $87 \mathrm{wt} \%$ PZT and $13 \mathrm{wt} \%$ resin was used and the weight reduction was measured according to changes in temperature using the TG-DTA equipment, as shown in Fig. 4. The weight started to decrease at $120^{\circ} \mathrm{C}$ and the resin was sufficiently removed at $500^{\circ} \mathrm{C}$. As a result of the DTA measurement, the exothermic peaks of the polymer were observed at $323^{\circ} \mathrm{C}$ and $488^{\circ} \mathrm{C}$, and a heat treatment profile was required to ensure a sufficient holding time at this temperature range. In the TGA measurement results, there was a flat section at about $500^{\circ} \mathrm{C}$.

\subsection{Suspension density evaluation and surface analysis results according to mixing ratio}

Figure 5 shows the density measurement graph according to the PZT powder content. The sample with $80 \mathrm{wt} \%$ powder content showed a density of approximately $6.35 \mathrm{~g} / \mathrm{cm}^{3}$. Moreover, as the powder content increased, the density improved to $7.15 \mathrm{~g} / \mathrm{cm}^{3}$ at $85 \mathrm{wt} \%, 7.46 \mathrm{~g} / \mathrm{cm}^{3}$ at $87 \mathrm{wt} \%$, and $7.56 \mathrm{~g} / \mathrm{cm}^{3}$ at $88 \mathrm{wt} \%$. The theoretical density of PZT was 7.7 $\mathrm{g} / \mathrm{cm}^{3}$, and the relative density was $97 \%$ for $87 \mathrm{wt} \%$, and $98 \%$ for $88 \mathrm{wt} \%$.

Figure 6 shows the result of investigating the porosity shapes of the sintered body by performing the SEM analysis between 80 and 88 wt\% of the powder content. Fig. 6(a) shows an image of the surface of the sample having $80 \mathrm{wt} \%$ powder content. It shows that many open channels of pores have been formed. Fig. 6(b) shows an image of the sample having $82 \mathrm{wt} \%$ powder content, and confirms that, although the porosity decreases as the solid content increases, the density is still low. Figs. 6(c) and (d) show the samples having 87 and 88 wt\% powder content, respectively. They show

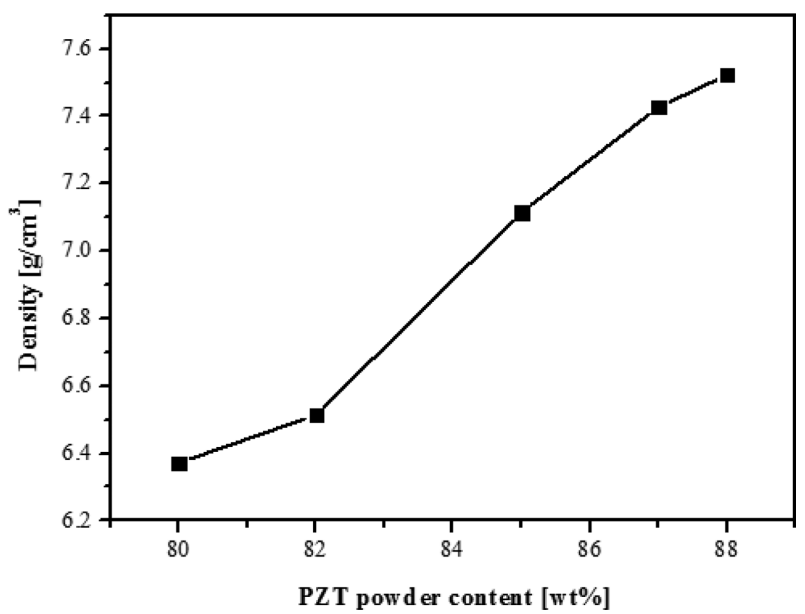

Fig. 5. Density changes for the PZT powder contents of 80 , $82,85,87$, and $88 \mathrm{wt} \%$. 

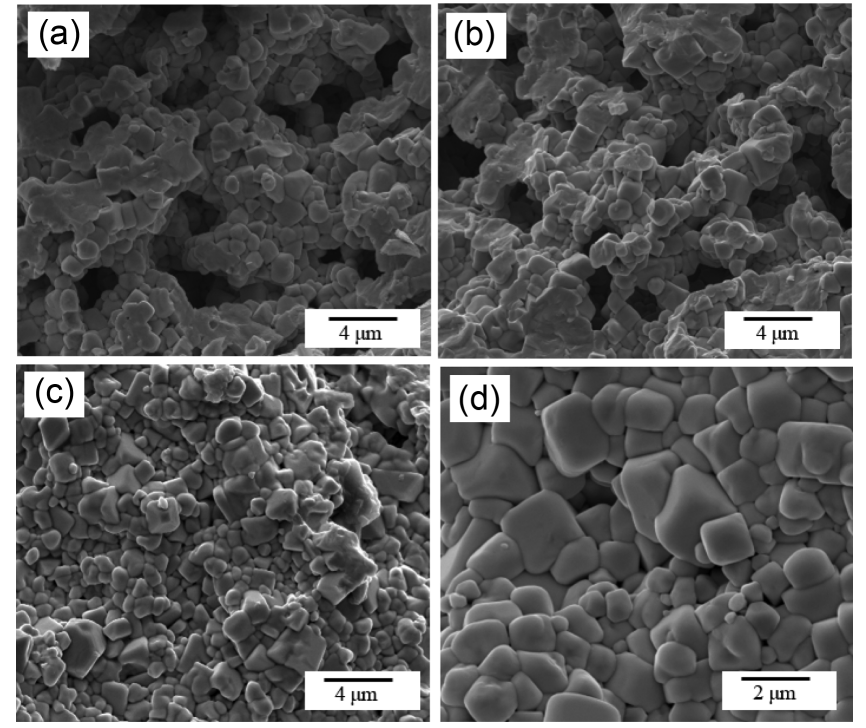

Fig. 6. SEM microstructures of the surface with the PZT powder contents of $80,82,85,87 \mathrm{wt} \%$.

excellent density characteristic with almost no porosity and no channels. They show identical characteristics as the results of the density measurement in Fig. 5.

A specimen having a UV-cured PZT: resin ratio of $87: 13$ was sintered to measure the shrinkage before and after sintering. The $\mathrm{X} \times \mathrm{Y} \times \mathrm{Z}$ size of the test piece before sintering is $5 \times 5 \times 1 \mathrm{~mm}$ and the size after sintering is $4.03 \times 4.07 \times$ $0.79 \mathrm{~mm}$. The contraction rate is $19.4 \%$ for $\mathrm{X}, 18.6 \%$ for $\mathrm{Y}$, and $21 \%$ for $\mathrm{Z}$. The volume shrinkage was measured as $49 \%$.

\subsection{PZT Crystal structure analysis of sintered sam-} ples

Figure 7 shows the XRD patterns according to the PZT powder content. All the samples had perovskite crystal structures without any different secondary phase. When the PZT powder content was changed from $80 \mathrm{wt} \%$ to $88 \mathrm{wt} \%$ in

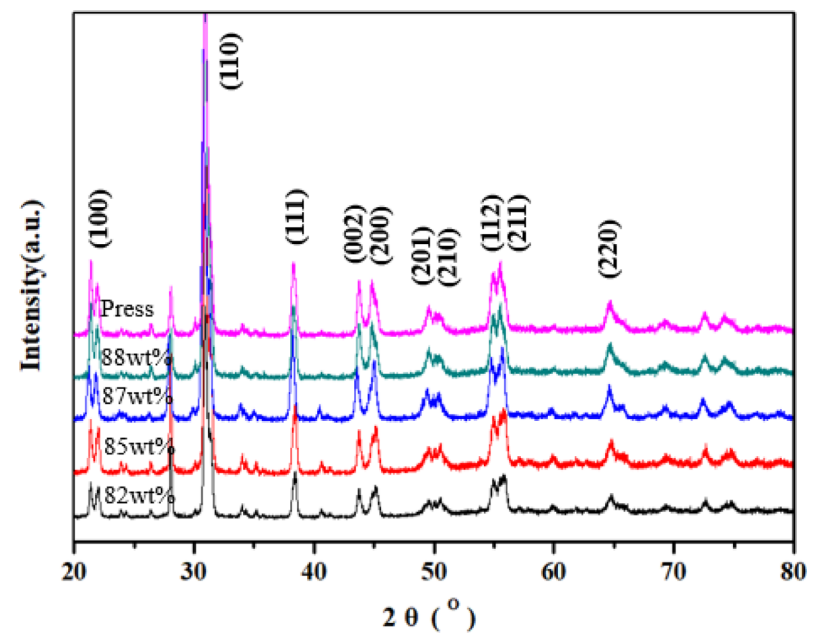

Fig. 7. XRD patterns of sintered ceramics with different PZT contents. the slurry, the crystallinity of the sintered body increased from $32 \%$ to $92 \%$ of the theoretical value. Crystallinity increased proportionally with increasing solids content, but crystal saturation was observed above $87 \mathrm{wt} \%$.

\section{Conclusions}

This study fabricated PZT suspensions for photo-curable 3D printing and evaluated their characteristics. Using a high-shear mixer, the PZT, photopolymer, photo-initiator, and dispersant were mixed, and the viscosity characteristic was investigated according to the changes in powder content. To determine an appropriate dispersant content, the dispersant was mixed at 1,3 , and $5 \mathrm{wt} \%$ of the powder and the dispersion test was conducted for $2 \mathrm{~h}$. Consequently, it was observed that the precipitation did not occur at $3 \mathrm{wt} \%$ or higher. Through the TGA analysis, it was confirmed that the photopolymer showed weight reduction between 120 and $500^{\circ} \mathrm{C}$, thereby providing a debinding heat-treatment profile. The fabricated suspensions were cured using UV light and the polymer was removed through debinding. Subsequently, the density and surface characteristics were analyzed by using the Archimedes method and SEM. Consequently, compared with the theoretical density, an excellent characteristic of $97 \%$ was obtained at a powder content of $87 \mathrm{wt} \%$. Through the XRD analysis, it was confirmed that the crystallizability improved as the solid content increased. At the mixing ratio of $87 \mathrm{wt} \%$ powder and 13 wt\% photo-curable resin, the viscosity was $3,100 \mathrm{cps}$, confirming an appropriate viscosity characteristic as a stereolithography suspension for 3D printing.

\section{Acknowledgments}

This study was funded by the Ministry of Trade, Industry and Energy (MOTIE) of Korea and conducted under "the Competency Development Program for Industry Specialists," undertaken by Korean Institute for Advancement of Technology (KIAT). (No. P0002007, HRD program for 3D Printing based on 3D Printing Materials).

\section{REFERENCES}

1. B. Jaffe, W. R. Cook, and H. Jaffe, Piezoelectric Ceramics; pp. 135-81, Academic Press London and New York, 1997.

2. S.-E. Park and T. R. Shrout, "Ultrahigh Strain and Piezoelectric Behavior in Relaxor Based Ferroelectric Single Crystals," J. Appl. Phys., 82 [4] 1804-11 (1997).

3. D. W. Ji and S. J. Kim, "State-Dependent Pyroelectric and Thermal Expansion Coefficients in a PZT Rectangular Parallelepiped after Compressive Loading and Unloading," J. Mater. Sci., 49 [2] 766-75 (2014).

4. H. Kungl and M. J. Hoffmann, "Temperature Dependence of Poling Strain and Strain under High Electric Fields in LaSr-doped Morphotropic PZT and its Relation to Changes in Structural Characteristics," Acta Mater., 55 [17] 5780 91 (2007). 
5. A. J. Bell, "Factors Influencing the Piezoelectric Behaviour of PZT and other "Morphotropic Phase Boundary" Ferroelectrics," J. Mater. Sci., 41 [1] 13-25 (2006).

6. T. R. Howarth and R. Y. Ting, "Electroacoustic Evaluation of 1 - 3 Piezocomposite SonoPanel ${ }^{\mathrm{TM}}$ Materials," IEEE Trans. Ultrason. Ferroelectr. Freq. Control, 7 [4] 886-94 (2000).

7. T. K. Ha, H.-J. Sung, S. Ahn, and Y. W. Chang, "Powder Injection Molding Technology (in Korean)," Trans. Mater. Process., 12 [6] 521-28 (2003).

8. R. E. Newnham, D. P. Skinner, and L. E. Cross, "Connectivity and Piezoelectric-Pyro-Electric Composites," Mater. Res. Bull., 13 [5] 525-36 (1978).

9. X. Jiang, K. Kim, S. Zhang, J. Johnson, and G. Salazar, "High-Temperature Piezoelectric Sensing," Sensors, 14 [1] 144-69 (2013).

10. C.-J. Bae and J. W. Halloran, "Integrally Cored Ceramic Mold Fabricated by Ceramic Stereolithography," Int. J. Appl. Ceram. Technol., 8 [6] 1255-62 (2011).

11. A. Zocca, P. Colombo, C. M. Gomes, and J. Gunster, "Additive Manufacturing of Ceramics: Issues, Potentialities, and Opportunities," J. Am. Ceram. Soc., 98 [7] 1983-2001
(2015).

12. T. Friedel, N. Travitzky, F. Niebling, M. Scheffler, and P. Greil, "Fabrication of Polymer Derived Ceramic Parts by Selective Laser Curing," J. Eur. Ceram. Soc., 25 [2-3] 193-97 (2005).

13. J. Deckers, J. Vleugels, and J.-P. Kruth, "Additive Manufacturing of Ceramics: A Review," J. Ceram. Sci. Tech., 5 [4] 245-60 (2014).

14. M. L. Griffith and J. W. Halloran, "Freeform Fabrication of Ceramics via Stereolithography," J. Am. Ceram. Soc., 79 [10] 2601-8 (1996).

15. C. Decker, "UV-Radiation Curing Chemistry," Pigm. Resin Technol., 30 [5] 278-86 (2001).

16. H. Ji and H. S. Lee, "Comparison of the Viscosity of Ceramic Slurries Using a Rotational Rheometerand a Vibrational Viscometer," J. Korean Ceram. Soc., 49 [6] 542-48 (2012).

17. J. W. Halloran, "Ceramic Stereolithography: Additive Manufacturing for Ceramics by Photopolymerization," Annu. Rev. Mater. Res., 46 19-40 (2016).

18. C.-J. Bae and J. W. Halloran, "Integrally Cored Ceramic Mold Fabricated by Ceramic Stereolithography," Int. J. Appl. Ceram. Technol., 8 [6] 1289-95 (2011). 